Article

\title{
Metal-Carbon-CNF Composites Obtained by Catalytic Pyrolysis of Urban Plastic Residues as Electro-Catalysts for the Reduction of $\mathrm{CO}_{2}$
}

\author{
Jesica Castelo-Quibén $\left.{ }^{(}\right)$, Abdelhakim Elmouwahidi, Francisco J. Maldonado-Hódar, \\ Francisco Carrasco-Marín (iD) and Agustín F. Pérez-Cadenas * (iD \\ Carbon Materials Research Group, Department of Inorganic Chemistry, Faculty of Sciences, University of \\ Granada, Avenida de Fuentenueva, s/n, Granada ES18071, Spain; jesicacastelo@ugr.es (J.C.-Q.); \\ aelmouwahidi@ugr.es (A.E.); fjmaldon@ugr.es (F.J.M.-H.); fmarin@ugr.es (F.C.-M.) \\ * Correspondence: afperez@ugr.es; Tel.: +34-958-24-33-16
}

Received: 26 March 2018; Accepted: 7 May 2018; Published: 9 May 2018

\begin{abstract}
Metal-carbon-carbon nanofibers composites obtained by catalytic pyrolysis of urban plastic residues have been prepared using $\mathrm{Fe}, \mathrm{Co}$ or $\mathrm{Ni}$ as pyrolitic catalysts. The composite materials have been fully characterized from a textural and chemical point of view. The proportion of carbon nanofibers and the final content of carbon phases depend on the used pyrolitic metal with Ni being the most active pyrolitic catalysts. The composites show the electro-catalyst activity in the $\mathrm{CO}_{2}$ reduction to hydrocarbons, favoring all the formation of $\mathrm{C} 1$ to $\mathrm{C} 4$ hydrocarbons. The tendency of this activity is in accordance with the apparent faradaic efficiencies and the linear sweep voltammetries. The cobalt-based composite shows high selectivity to C3 hydrocarbons within this group of compounds.
\end{abstract}

Keywords: carbon dioxide; $\mathrm{CO}_{2}$ electro-reduction; metal-carbon-CNF composites; plastic waste; carbon-based electrodes; carbon nanofibers

\section{Introduction}

The increase of $\mathrm{CO}_{2}$ concentration in the atmosphere is thought to be one of the main causes of global climate change [1]. In particular, the $\mathrm{CO}_{2}$ emission from the use of fossil fuels contributes to the increasing concentration because it establishes a continuous net increase in the natural cycle of the tropospheric carbon.

There are different strategies proposed to control this issue [2] being the most extended the $\mathrm{CO}_{2}$ storage, and the $\mathrm{CO}_{2}$ transformation to other valuable products, together with the implementation of renewable energies.

On the other hand, renewable energy sources are supposed to be a replacement, but nowadays they are not producing the constant currents that fossil fuels provide. For this reason, the storage of surplus electrical energy produced during the peak production periods, and its release during peak demand periods, should be crucial. In this manner, extensive research effort has focused on battery storage [3]. However, battery manufacturing requires a lot of resources, reducing their contribution to controlling $\mathrm{CO}_{2}$ emission, and its life is relatively limited. Furthermore, recycling of their components is also a challenge.

One possible option to address the problem of temporary storing and local surplus of renewable energy is the electro-catalytic reduction of $\mathrm{CO}_{2}$ to hydrocarbons in water [4]. In this process, the water is split to provide the required hydrogen atoms, which react with $\mathrm{CO}_{2}$ to form hydrocarbons that can be used directly in the existing infrastructure of fuel transportation as well as in storing the renewable energy. 
The direct electrochemical reduction of $\mathrm{CO}_{2}$ in aqueous solution has been typically studied with metal electrodes like $\mathrm{Cu}, \mathrm{Au}$, or $\mathrm{Sn}$ during the past few decades [5-10]. Copper electrodes have been found to be quite good in the reduction of $\mathrm{CO}_{2}$ to hydrocarbons, although the Faradaic efficiency was still low as a result of the dissociation of $\mathrm{H}_{2} \mathrm{O}$ to $\mathrm{H}_{2}$ [9]. More recently, metallic electrodes derived from corresponding metal oxides, like $\mathrm{SnO}_{x}$, seemed to show promising results in certain catalytic performance for $\mathrm{CO}_{2}$ reduction [11-13], and only a few transition-metal oxides such as $\mathrm{TiO}_{2}, \mathrm{FeO}_{\mathrm{x}}$ and $\mathrm{Cu}_{2} \mathrm{O}$ have been reported as potential electro-catalysts for this application [14].

Alternatively, the application of carbon materials in electro-catalytic $\mathrm{CO}_{2}$ reduction process is a plausible option, which has been tested with platinum catalysts supported on carbon nanotubes, carbon cloth or carbon black [15,16], and even metal-free carbons [17]. Centi et al. [15] showed for the first time the possibility of electro-catalytically converting $\mathrm{CO}_{2}$ to hydrocarbons with carbon chains $>\mathrm{C} 5$, and with product distributions which do not follow the Anderson-Schulz-Flory distribution model typical for Fischer-Tropsch synthesis. Li et al. [17] addressed nanoporous S-doped and S,N-codoped carbons as catalysts for electrochemical reduction $\mathrm{CO}_{2}$ to $\mathrm{CO}$ and $\mathrm{CH}_{4}$, where the negative charge on the pyridinic nitrogen groups promotes electron-proton transfer to $\mathrm{CO}_{2}$ leading to $\mathrm{COOH}^{*}$ intermediates, which are further reduced to CO.

Carbon gels doped with transition metals have also shown activity in this reaction $[18,19]$. Although this $\mathrm{CO}_{2}$ reduction mechanism is still being studied [20], the products obtained in the direct electrochemical reduction of $\mathrm{CO}_{2}$ to hydrocarbons can achieve several carbon atoms [21]. Regarding the hydrocarbon selectivity, recently [22,23], a high selectivity to C3-hydrocarbons among the detected products has been reported using $\mathrm{Co}$ - and Fe-carbon electrodes. Moreover, Fe-carbon electrodes have shown a well-fitted linear correlation between the average crystal sizes of iron and the faradaic efficiencies: the smaller the crystal size, the higher the faradaic efficiency [23].

On the other hand, the large amounts of plastic residue is also a very important environmental problem, and the out-of-control combustion method should not be an option, because it would increase the $\mathrm{CO}_{2}$ atmospheric and cause other environmental pollution problems [24]. Within these materials, polyethylene (HDPE or LDPE) based plastic bags represent a significant proportion. There are several propositions for the recycling of plastic waste, as their transformation in fuels [25], the recovering of valuable components [26] of their transformation in carbon-based materials or composites [27]. However, the direct application of carbon-metal composites, obtained from real world plastic waste as $\mathrm{CO}_{2}$ electro-catalysts have not been reported yet. One important advantage of these composite materials as electro-catalysts compared to other proposed carbon based electro-catalysts is the low cost of the raw material since they can be obtained directly from the plastic waste. Therefore, with this proposal, we are focusing our actions on the $\mathrm{CO}_{2}$ problem twice, (i) researching in its electro-catalytic transformation to hydrocarbons; and (ii) proposing a way for the transformation of LDPE based residues in valuable products.

In the present work, we demonstrate the application of metal-carbon-carbon nanofibers composites obtained from real world plastic waste as promising electrodes in the electro-catalytic reduction of $\mathrm{CO}_{2}$ to hydrocarbons.

\section{Results and Discussion}

\subsection{Textural and Chemical Characterization of the Composites}

Table 1 summarizes the surface areas and pore volumes of the composites. These materials show apparent surface areas between 44 and $80 \mathrm{~m}^{2} \mathrm{~g}^{-1}$, and an extremely low microporosity, in fact, their $\mathrm{N}_{2}$ adsorption isotherms show typical type IV shapes.

SEM images of the composites are collected in Figure 1. The morphology consists in a mixture of carbon particles pseudo-flats, overlapped among them from where carbon-nanofibers (CNF) emerge. These CNF are clearly visible in sample PNi, where they are longer than in the other composites, although by HRTEM (Figure 2) the presence of CNF has been detected in all the samples being these $\mathrm{CNF}$ clearly hollow and maintaining the metal particle inside of them in most cases. Moreover, 
the main metal particles $\mathrm{Fe}$, Co or Ni are very well dispersed throughout the carbon matrix (Figure 2), showing a wide range of sizes but all within the nanometric scale.

Table 1. Name, surface area and pore volumes of the composites.

\begin{tabular}{ccccc}
\hline Sample & $\mathbf{S}_{\text {BET }}\left(\mathbf{m}^{\mathbf{2}} \mathbf{g}^{-\mathbf{1}}\right)$ & $\mathbf{W}_{\mathbf{0}}\left(\mathbf{c m}^{\mathbf{3}} \mathbf{g}^{\mathbf{- 1}}\right)$ & $\mathbf{L}_{\mathbf{0}}(\mathbf{n m})$ & $\mathbf{V}_{\mathbf{0 . 9 5}}\left(\mathbf{c m}^{\mathbf{3}} \mathbf{g}^{\mathbf{- 1}}\right)$ \\
\hline PFe & 44 & 0.01 & 2.08 & 0.100 \\
PCo & 80 & 0.02 & 2.16 & 0.189 \\
PNi & 44 & 0.01 & 2.18 & 0.149 \\
\hline
\end{tabular}

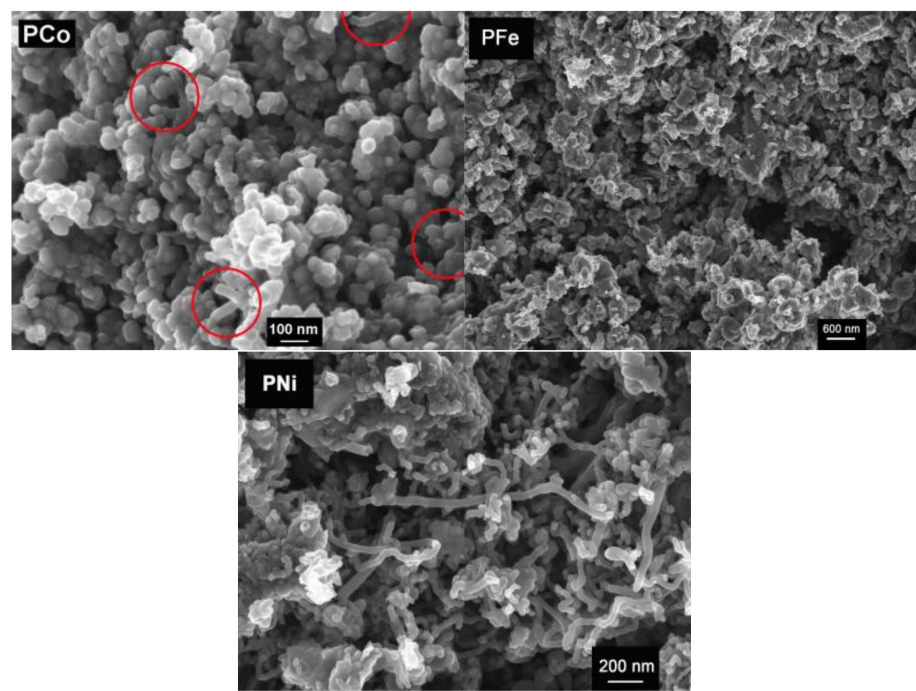

Figure 1. SEM microphotographs showing the morphology of the different composites. Red circles indicate CNF in sample PCo.
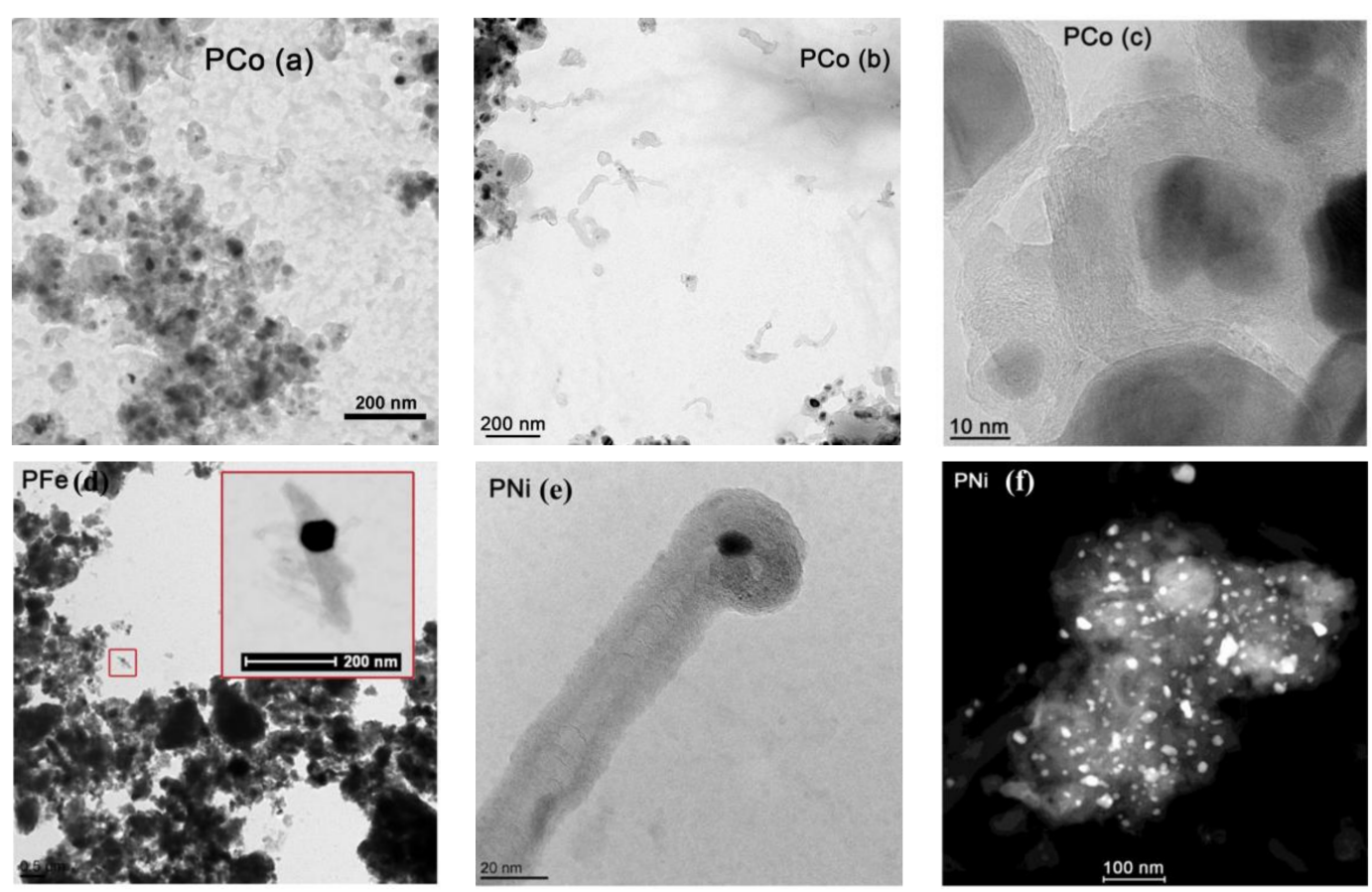

Figure 2. (a-e) High-resolution transmission electron microscopy (HRTEM) images of the composites; (f) scanning transmission electron microscopy (STEM) image, using a high angle annular dark field (HAADF) detector of the PNi sample. 
Regarding the metal chemical composition of the composites, Table 2 collects the ICP analysis of the samples. Firstly, it is observed that the content of the pyrolitic catalyst is not the same among the composites which denote a different catalytic behavior and, therefore, indicates different yield in carbon phases. In this line, composite PFe shows the highest metal loading, followed by PCo and lastly by PNi. Thus, small amounts of $\mathrm{Fe}, \mathrm{Co}$ or $\mathrm{Ni}$ are present in all the samples which are in agreement with other studies where the metal content of commercial plastic bags have been analyzed [28]. Much more significant are the relatively high contents of $\mathrm{Ca}$ and $\mathrm{K}$; these metals are typical additives of the commercial plastic bags to enhance stiffness and mechanical properties [29].

Table 2. Metal content of the composites determined by inductively coupled plasma optical emission spectrometry (ICP-OES).

\begin{tabular}{cccccc}
\hline Sample & Ca $_{\text {ICP }}$ (wt. \%) & Co $_{\text {ICP }}$ (wt. \%) & Fe $_{\text {ICP }}$ (wt. \%) & K ICP $_{\text {I wt. } \%)}$ & Ni $_{\text {ICP }}$ (wt. \%) \\
\hline PCo & 2.31 & 9.93 & 0.36 & 2.56 & 0.12 \\
PFe & 3.75 & 0.07 & 15.92 & 4.68 & 0.43 \\
PNi & 1.56 & 0.02 & 0.29 & 2.02 & 6.52 \\
\hline
\end{tabular}

On the other site, $\mathrm{Fe}, \mathrm{Co}$, and Ni nanoparticles are mainly reduced in zero oxidation state (Figure 3) and situated in both of the carbon phases. This conclusion results from the corresponding XRD peaks that are clearly visible at $44.7^{\circ}, 44.4^{\circ}$ and $44.5^{\circ}$ for $\mathrm{Fe}, \mathrm{Co}$, and $\mathrm{Ni}$, respectively, while practically negligible amounts of these metals were detected by XPS (Table 3). Moreover, the aforementioned Fe, Co or Ni nanoparticles situated in the amorphous carbon phase are covered by graphitic clusters as it has been observed by HRTEM (Figure 2c), which is due to the fact that these metals are also the catalytic metals of graphitization $[30,31]$.

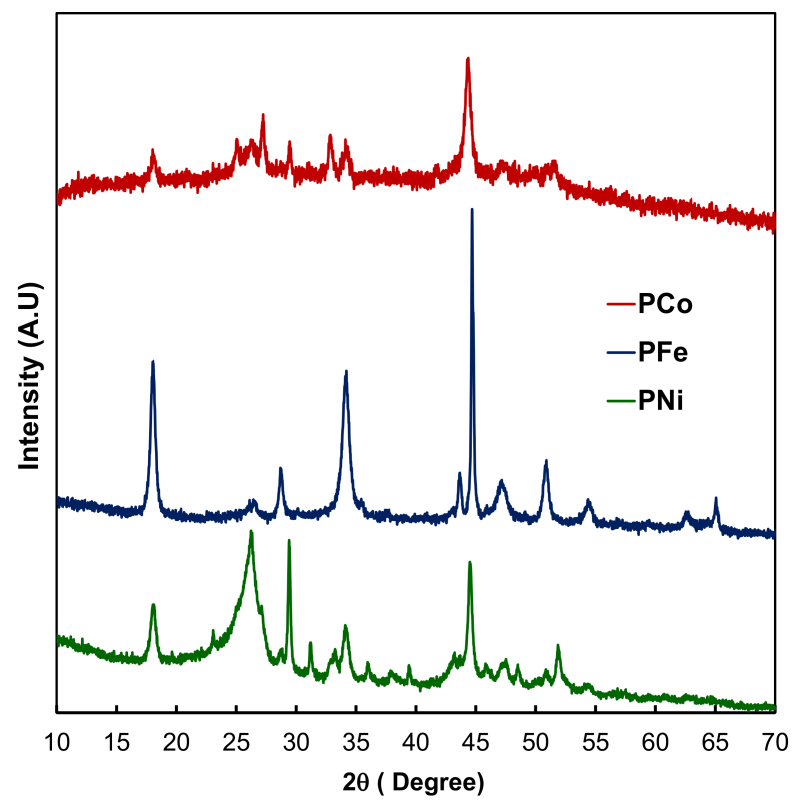

Figure 3. XRD patterns of the composites.

Table 3. Superficial chemical content of the composites determined by XPS.

\begin{tabular}{cccccccc}
\hline Sample & C (wt. \%) & O (wt. \%) & K (wt. \%) & Ca (wt. \%) & Co (wt. \%) & Fe (wt. \%) & Ni (wt. \%) \\
\hline PCo & 87.71 & 6.93 & 2.05 & 2.97 & 0.34 & 0.00 & 0.00 \\
PFe & 82.21 & 8.53 & 5.35 & 3.81 & 0.00 & 0.10 & 0.00 \\
PNi & 89.84 & 4.12 & 3.91 & 1.98 & 0.00 & 0.00 & 0.15 \\
\hline
\end{tabular}


Nevertheless, the case of $\mathrm{Ca}$ and $\mathrm{K}$ are very different, also between them: Ca particles are clearly $\mathrm{Ca}$ (II) forming part of $\mathrm{Ca}(\mathrm{OH})_{2} ; \mathrm{XRD}$ peaks at 18 and $34^{\circ}$ seem to confirm it (Figure 3 ) and the $\mathrm{Ca} 2 \mathrm{p}_{3 / 2}$ XPS peak at $348.4 \mathrm{eV}$ as well (Figure 4). However, $\mathrm{K}$ particles have not been detected by XRD, which means that its sizes should be lower than $4 \mathrm{~nm}$ approx., however, $\mathrm{K}(0)$ peaks have been clearly detected by XPS at $293.7 \mathrm{eV}$ (Figure 4; only XPS spectra of PNi has been included in this Figure being the corresponding PCo and PFe XPS spectra very similar to this one). A plausible explanation would be that $\mathrm{K}(0)$ nanoclusters or atoms could be mainly inserted between the graphenic layers, as it is only in this situation that they could they keep the zero oxidation state after the final washing treatment of the samples. Finally, it should be noted that both data of chemical analysis, ICP and XPS are in good agreement: PNi is the composite with the lowest transition metal content obtained by ICP analysis and with the highest carbon content determined by XPS, while in the case of PFe, opposites occur. On the other hand, both $\mathrm{K}$ and $\mathrm{Ca}$ are homogeneously distributed throughout the composite since similar contents are obtained from both techniques.

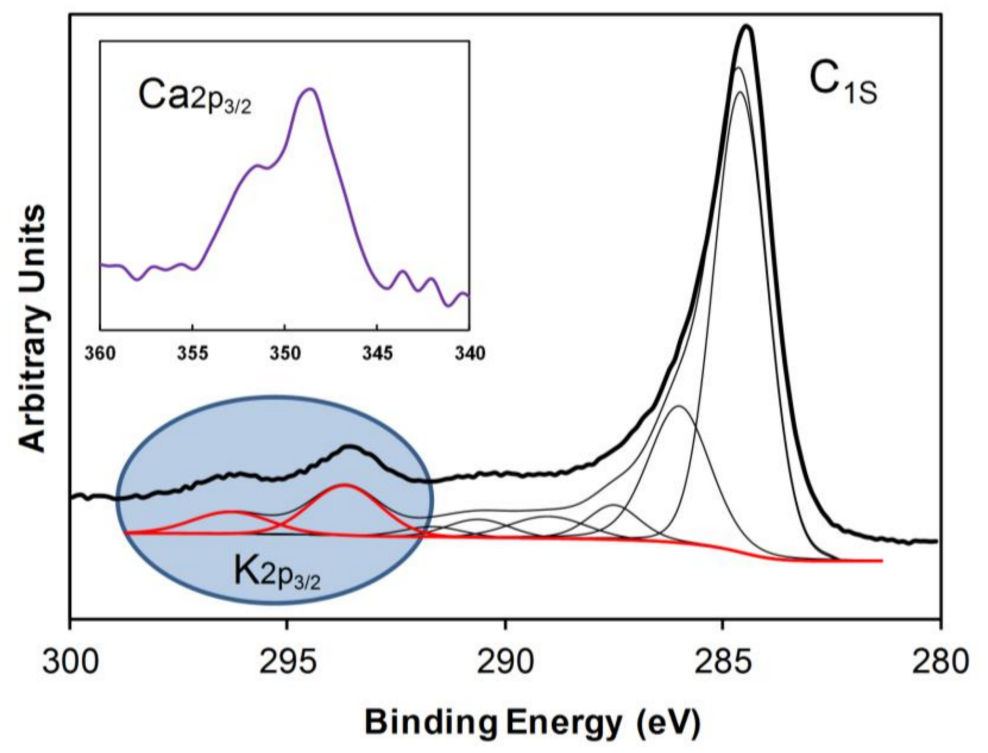

Figure 4. XPS spectra of composite PNi.

\subsection{Electro-Reduction of $\mathrm{CO}_{2}$}

The three composites were used as a cathode in the electro-catalytic reduction of $\mathrm{CO}_{2}$. A graphite sheet with dimensions of $50 \mathrm{~mm} \times 8 \mathrm{~mm}$ was also tested as a blank cathode in the electro-catalytic reduction of $\mathrm{CO}_{2}$. The products analyzed in the gas phase of the reactor were the following: methane $\left(\mathrm{CH}_{4}\right)$, ethane $\left(\mathrm{C}_{2} \mathrm{H}_{6}\right)$, ethene $\left(\mathrm{C}_{2} \mathrm{H}_{4}\right)$, propane $\left(\mathrm{C}_{3} \mathrm{H}_{8}\right)$, propene $\left(\mathrm{C}_{3} \mathrm{H}_{6}\right)$, propyne $\left(\mathrm{C}_{3} \mathrm{H}_{4}\right)$ and n-butane $\left(\mathrm{C}_{4} \mathrm{H}_{10}\right)$; Figure 5 shows the evolution of these compounds vs. the reaction time.

The molar production has also been described regarding C1, C2, C3 and C4 hydrocarbons, 1 to 4 being the number of carbon atoms in the molecules to simplify the discussion about the reaction selectivity. Nevertheless, methane was the major product in all of the cases, and minor amounts of other detected products (probably $\mathrm{C} 4$ isomers, or $\mathrm{C} 5$, hydrocarbons) have not been quantified. Thus, it is necessary to clarify that when an electrolyte free from dissolved $\mathrm{CO}_{2}$ was used (that is, carrying out the reaction under Ar-saturated solution), hydrocarbons, $\mathrm{CO}$ or $\mathrm{CO}_{2}$ were not detected in any cases. Similarly, in the presence of $\mathrm{CO}_{2}$ (normal experimental reaction conditions) and using only the pure graphite cathode, no hydrocarbons were detected. Regarding the molar production, although the surface area and pore volume of the composites were relatively low, the adsorption of a part of the product in the porous structure of the carbon phases could never be ruled out. 

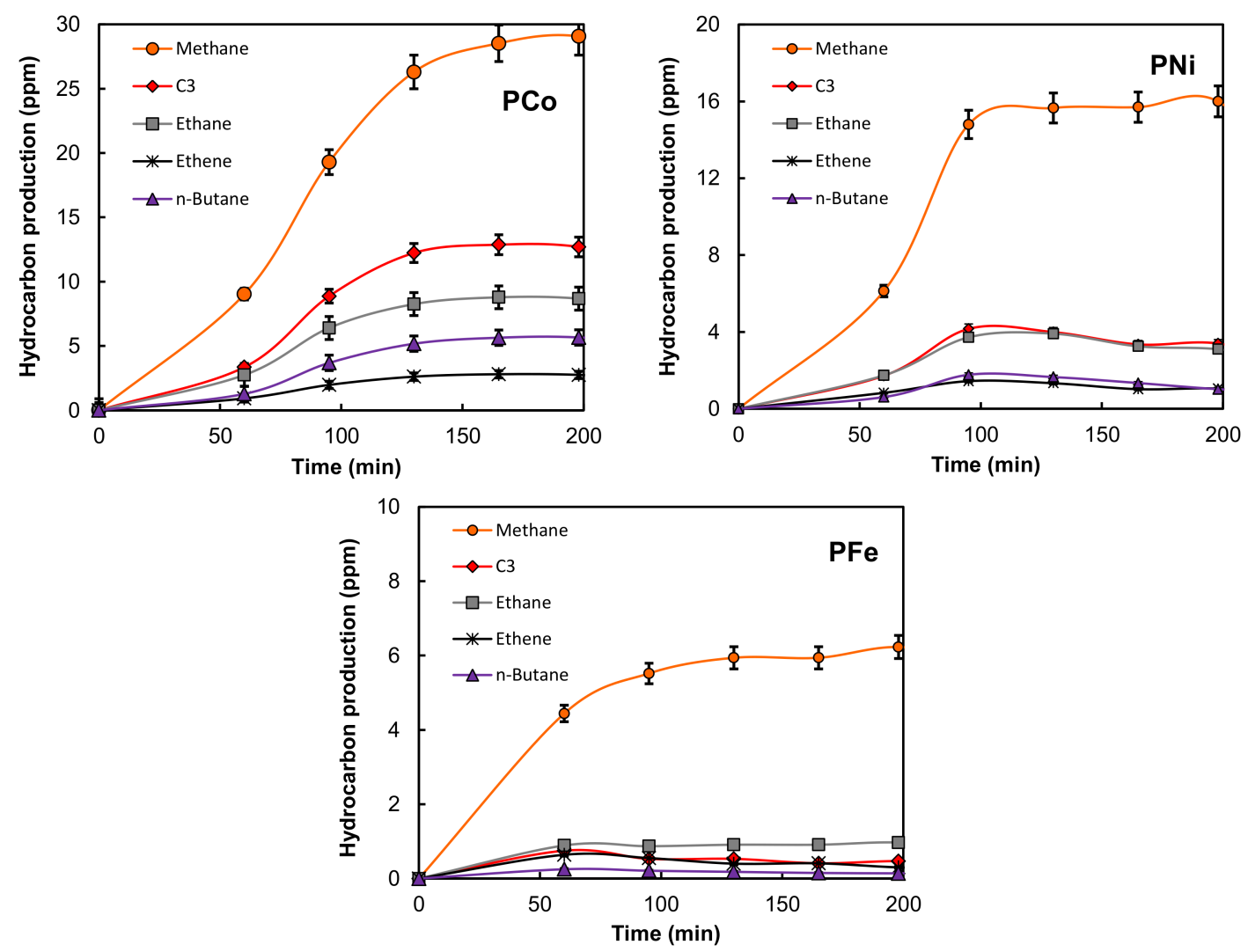

Figure 5. Product distribution (ppm) vs. reaction time.

Data of the total molar productions of hydrocarbons in the reactor are collected in Figure 6; from this Figure, an adequate comparison of the electro-catalytic behavior of these composites is not straightforward because they do not present similar textural characteristics or metal contents. On the other side, we can see that the rate of hydrocarbon formation tends to decrease after $\sim 100 \mathrm{~min}$ of reaction for PNi and PFe, and somewhat later for PCo. This type of catalytic behavior has been previously observed [22] and explained by a high formation of $\mathrm{H}_{2}$ and $\mathrm{O}_{2}$, which can provoke a dilution effect of the hydrocarbon formation in the gas phase of the reactor [32]. In any case, the following catalytic tendency can clearly be observed: $\mathrm{PCo}>\mathrm{PNi}>\mathrm{PFe}$, which is in accordance with the apparent faradaic efficiencies calculated at $95 \mathrm{~min}$ of reaction time (Table 4). It is important to clarify that that only the detected hydrocarbons (nor $\mathrm{H}_{2}$ neither $\mathrm{O}_{2}$ formation) have been included in the faradaic efficiencies calculations. Faradaic efficiencies of this order have been previously obtained with Fe and Co doped carbon gels [22,23].

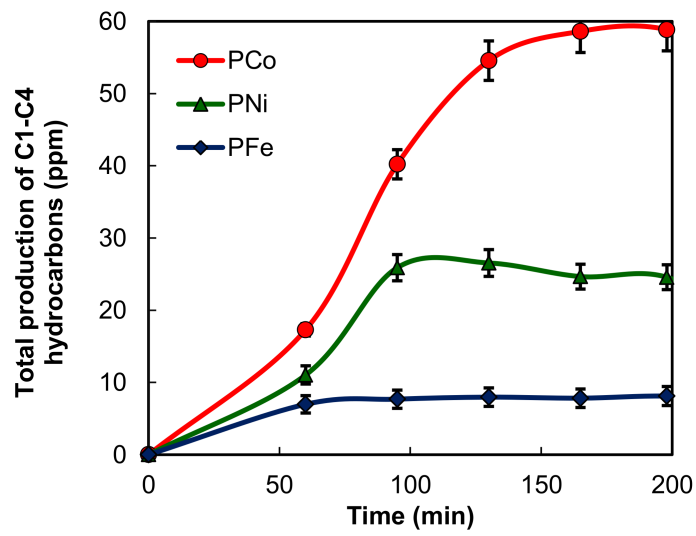

Figure 6. Molar production vs. time obtained with the electro-catalysts. 
Table 4. Mean crystal particle size $\left(\mathrm{d}_{\mathrm{XRD}}\right)$, and apparent faradaic efficiencies (F.E.) for the electro-catalytic $\mathrm{CO}_{2}$ reduction determined at $95 \mathrm{~min}$ of reaction time at $-1.65 \mathrm{~V}$ vs. $\mathrm{Ag} / \mathrm{AgCl}$.

\begin{tabular}{ccc}
\hline Composite & $\mathbf{d}_{\mathbf{X R D}}{ }^{*}(\mathbf{n m})$ & F.E. (\%) \\
\hline PCo & 13.6 & 0.46 \\
PNi & 20.7 & 0.40 \\
PFe & 39.4 & 0.06 \\
\hline
\end{tabular}

$\left({ }^{*}\right) \mathrm{Co}, \mathrm{Ni}$ or $\mathrm{Fe}$, respectively.

Therefore, the current findings demonstrate that all composites work as electro-catalysts in this reaction and that they are able to produce the $\mathrm{CO}_{2}$ transformation to at least $\mathrm{C} 4$ hydrocarbons. Moreover, the composite PCo exhibits high selectivity to C3 products (Figure 7) within this group of detected products, which is in accordance with a recent finding with another type of Co doped carbon materials [22]. On the other hand, although PNi is mainly selective to $\mathrm{CH}_{4}$, the amount of C3 produced was also higher than C2. Finally, composite PFe was the least active catalyst, and it was also least selective to long chain hydrocarbons, despite it having the highest metal loading (Table 2). As previously reported, this behavior is most likely due to its large mean crystal size of Fe (Table 4) [23]. In this line, it should be noted that this composite has a mean metal particle size much larger than the other samples. Figure 8 compares the LSV curves of $\mathrm{CO}_{2}$ reduction obtained with all the electro-catalysts. The strong increase of the current values at $-1.65 \mathrm{~V}$ of the composite PFe denotes a low electro-catalytic capacity of this cathode in comparison with the other two samples.

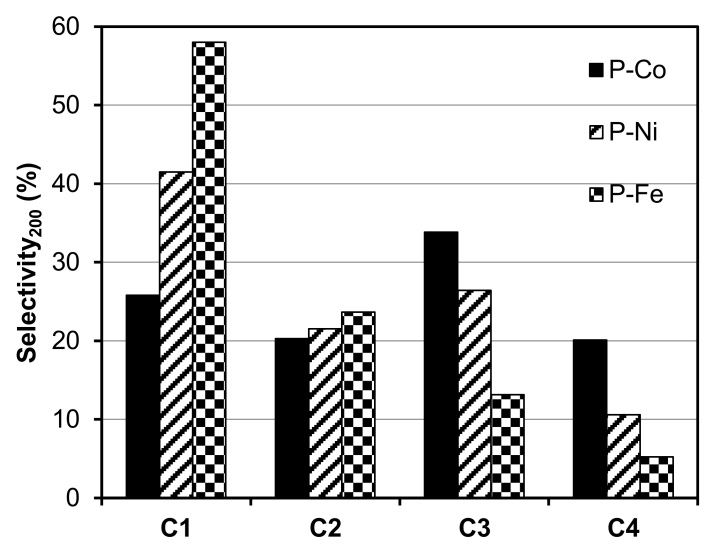

Figure 7. Product distribution (\%) in terms of carbon selectivity in gas phase products after $200 \mathrm{~min}$ of reaction time.

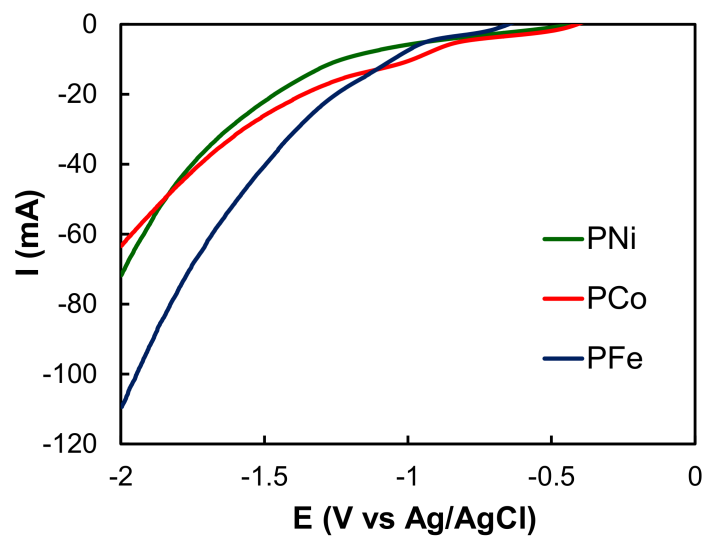

Figure 8. Linear sweep voltammetries obtained from the equilibrium electrode potential to a negative electric potential of $-2.00 \mathrm{~V}$ vs. $\mathrm{Ag} / \mathrm{AgCl}$. Scan rate: $5 \mathrm{mV} / \mathrm{s}$. Fresh electrodes in $\mathrm{CO}_{2}$ saturated $0.1 \mathrm{M} \mathrm{KHCO}_{3}$. 
Finally, all these cathodes were used in a second run of reaction, renovating the electrolyte and saturating with $\mathrm{CO}_{2}$; all of them again showed similar profiles from those collected in Figure 6. After drying, no significant weight differences were detected between the cathodes after the first and the second runs. Transition metal leaching in the liquid solutions was studied in all cases by ICP-OES; the detected metal concentrations in the liquids always being lower than $100 \mathrm{ppb}$.

This work shows that the preparation of $\mathrm{CO}_{2}$ electro-catalyst from real world plastic waste is achievable and although both the preparation method and the electro-chemical application still needs improvement and/or optimization for a real application, the obtained results are very promising. To our knowledge, the direct application of metal-carbon-CNF composites obtained from the real world plastic waste as $\mathrm{CO}_{2}$ electro-catalysts has not been reported yet.

\section{Materials and Methods}

Three different composites of metal-carbon-carbon nanofibers (-CNF) were prepared by a catalyzed pyrolysis of urban plastic residues which were thermally pre-treated in a closed reactor. These residues were plastic bags that were used in several well-known supermarkets in Spain, in which the polymer composition mainly consisted of low-density polyethylene (LDPE). Firstly, $10 \mathrm{~g}$ of the above-mentioned plastic bags were dissolved in $100 \mathrm{~mL}$ of o-xylene at $80^{\circ} \mathrm{C}$, and then $2 \mathrm{~g}$ of the catalysts precursor was added. The catalyst precursors were the corresponding hydroxides of $\mathrm{Fe}$, $\mathrm{Co}$ and $\mathrm{Ni}$, and the resulting mixture was stirred for $4 \mathrm{~h}$. After that, the o-xylene was evaporated, and the solid was heat treated at $350{ }^{\circ} \mathrm{C}$ in a closed reactor (Parr Instrument, Moline, IL, USA) (reactor ref. A1828HC2) for four hours. Finally, the so pre-treated solid was pyrolised under $\mathrm{N}_{2}$ flow $\left(300 \mathrm{~mL} \mathrm{~min}^{-1}\right)$ at $900{ }^{\circ} \mathrm{C}$. Before the characterization, the composites were washed with cool water several times. The obtained composites were named as PFe, PCo and PNi, being $\mathrm{Fe}, \mathrm{Co}$ and $\mathrm{Ni}$ the pyrolitic catalyst, respectively.

The metal contents of the composites were determined by inductively coupled plasma optical emission spectrometry (ICP-OES) using an ICP-OES PerkinElmer OPTIMA 8300 spectrometer (PerkinElmer, Madrid, Spain).

The samples were texturally characterized by physical adsorption of nitrogen, scanning electron microscopy (SEM), high resolution transmission electron microscopy (HRTEM), and chemically characterized by X-ray diffraction (XRD) and X-ray photoelectron spectroscopy (XPS) Linear sweep voltammetries (LSV) were also carried out.

$\mathrm{N}_{2}$ adsorption was carried out at $-196^{\circ} \mathrm{C}$. Prior to this measuring process, the samples were outgassed overnight at $110^{\circ} \mathrm{C}$ under high vacuum $\left(10^{-6} \mathrm{mbar}\right)$. The BET equation was applied to the $\mathrm{N}_{2}$ adsorption data obtaining the apparent surface area, $\mathrm{S}_{\mathrm{BET}}$. The Dubinin-Radushkevich (DR) equation was applied to the $\mathrm{N}_{2}$ adsorption data to obtain the corresponding micropore volume $\left(\mathrm{W}_{0}\right)$ and micropore mean width $\left(\mathrm{L}_{0}\right)$. Total pore volumes $\left(\mathrm{V}_{0.95}\right)$ were calculated from $\mathrm{N}_{2}$ adsorption isotherms at $-196^{\circ} \mathrm{C}$ and at 0.95 relative pressure.

SEM was carried out using a Zeiss SUPRA40VP scanning electron microscope (Carl Zeiss AG, Oberkochen, Germany), equipped with a secondary electron detector, back-scatter electron detector and by using an X-Max $50 \mathrm{~mm}$ energy dispersive X-ray microanalysis system. All the samples were crushed before performing this analysis.

HRTEM was performed using a FEI Titan G2 60-300 microscope (FEI, Eindhoven, The Netherlands) with a high brightness electron gun (X-FEG) operated at $300 \mathrm{kV}$ and equipped with a Cs image corrector (CEOS), and for analytical electron microscopy (AEM) a SUPER-X silicon-drift window-less EDX detector.

XRD analysis was carried out BRUKER D8 ADVANCE diffractometer (BRUKER, Rivas-Vaciamadrid, Spain) using $\mathrm{CuK} \alpha$ radiation. JCPDS files were searched to assign the different diffraction lines observed. Diffraction patterns were recorded between $10^{\circ}$ and $70^{\circ}(2 \theta)$ with a step of $0.02^{\circ}$ and a time per step of $96 \mathrm{~s}$. The average crystal size was determined using the Scherrer equation. 
XPS measurements of the metal-carbon-CNF composites were performed using a Physical Electronics ESCA 5701 (PHI, Chanhassen, MN, USA) equipped with a $\mathrm{MgK} \alpha \mathrm{X}$-ray source ( $\mathrm{hv}=1253.6 \mathrm{eV}$ ) operating at $12 \mathrm{kV}$ and $10 \mathrm{~mA}$ and a hemispherical electron analyzer. The obtained binding energy (BE) values were referred to the $C_{1 s}$ peak at $284.7 \mathrm{eV}$. A base pressure of $10^{-9}$ mbar was maintained during data acquisition. The survey and multi-region spectra were recorded at $\mathrm{C}_{1 \mathrm{~s}}, \mathrm{O}_{1 \mathrm{~s}}$, $\mathrm{Fe}_{2 p}, \mathrm{Co}_{2 p}, \mathrm{Ni}_{2 p}, \mathrm{~K}_{2 p}$ and $\mathrm{Ca}_{2 p}$ photoelectron peaks. Each spectral region was scanned enough times to obtain adequate signal-to-noise ratios. The spectra obtained after the background signal correction were fitted to Lorentzian and Gaussian curves to obtain the number of components, the position of each peak, and the peak areas.

Electro-catalytic reduction of $\mathrm{CO}_{2}$ to hydrocarbons was carried out in a three-electrode cell, working in batch mode at ambient temperature and pressure. The cell has $300 \mathrm{~cm}^{3}$ of total capacity. A Biologic VMP multichannel potentiostat (Bio-Logic Spain, Barcelona, Spain) was used to induce and control the electro-catalytic reaction by applying the selected potential differences over the electrodes. A platinum electrode was used as a counter electrode and $\mathrm{Ag} / \mathrm{AgCl}$ as a reference electrode. The used electrolyte was $150 \mathrm{~cm}^{3}$ of $\mathrm{CO}_{2}$-saturated $0.1 \mathrm{M}$ potassium bicarbonate aqueous solution. The setup was used in potentiostatic mode at $-1.65 \mathrm{~V}$, reproducing the voltage conditions of previous works [19]. Prior to the electro-catalytic $\mathrm{CO}_{2}$ reduction, the liquid phase was saturated through bubbling with $\mathrm{CO}_{2}$ for $3 \mathrm{~h}$. After saturation, the $\mathrm{pH}$ of the solution was 6.7. The $\mathrm{CO}_{2}$ feed and exit lines were closed off and the reactor was operated in the batch mode. The amount of composite used in the cathode as electro-catalyst (working electrode) was $80 \mathrm{mg}$ which was homogeneously pasted on both faces of a graphite sheet with dimensions of $50 \mathrm{~mm} \times 8 \mathrm{~mm}$. In the preparation of the cathode, the metal-carbon-CNF composite was mixed with the corresponding amount of polytetrafluoroethylene (PTFE) in a weight ratio of (80:7) using a PTFE (60\%) water solution. All working electrodes were kept in $0.1 \mathrm{M}$ potassium bicarbonate aqueous solution overnight before being used in the electro-reactor. The samples were also tested as electro-catalysts carrying out the reaction under Ar-saturated solution and, therefore, using electrolytes free of $\mathrm{CO}_{2}$.

The samples were also characterized by LSV (Bio-Logic Spain, Barcelona, Spain). The cathodic sweep analysis was conducted from the equilibrium electrode potential to negative electric potential of $-2.0 \mathrm{~V}$ vs. $\mathrm{Ag} / \mathrm{AgCl}$, with a scan rate of $5 \mathrm{mV} \mathrm{s}^{-1}$, using the same experimental conditions and reactor set-up for the electro-catalytic reduction of $\mathrm{CO}_{2}$.

The hydrocarbons produced by the electro-chemical reduction of $\mathrm{CO}_{2}$ were analyzed from the gas phase using a gas chromatograph (GC) (Bruker Española, Rivas-Vaciamadrid, Spain), where the gases were directly injected into the GC column using a gas recirculating pump for low flows. The GC (carrier gas: He, column: Chrompack Poraplot $\mathrm{Q}, 50 \mathrm{~m} \times 0.53 \mathrm{~mm}$ ) was equipped with a FID and TCD detectors. The distribution of gaseous products can be expressed in terms of the carbon selectivity as the amount of carbon atoms (from $\mathrm{CO}_{2}$ ) in a specific product relative to the total amount of carbon atoms in the detected hydrocarbons.

$$
S_{C_{i}}(\%)=\frac{i \cdot n_{C_{i}}}{\sum_{i} i \cdot n_{C_{i}}} \times 100 \%
$$

Here $n_{C i}$ represents the mol of product $C_{i}$, and $i$ the number of carbon atoms in that product.

The liquid phase was also analyzed by Headspace Gas Chromatography-Mass Spectrometry using another GC equipped with a HP-INNOWax $30 \mathrm{~m} \times 0.25 \mathrm{~mm} \times 0.25 \mu \mathrm{m}$ column, which was coupled to a MS-Triple quadrupole. The presence of carboxylic acids or alcohols of one to four carbon atoms were not detected.

\section{Conclusions}

Metal-carbon-CNF composites have been obtained from the urban plastic waste. The amount and type of carbon nanofibers and final carbon contents depend on the pyrolitic used metal: $\mathrm{Fe}$, Co or Ni. 
$\mathrm{Ni}$ catalysts yield the major amount of $\mathrm{CNF}$ and carbon phases in the composites. On the other hand, significant contents of $\mathrm{Ca}$ and $\mathrm{K}$ are also present in the composites, however, while $\mathrm{Ca}$ is forming part of $\mathrm{Ca}(\mathrm{OH})_{2}, \mathrm{~K}$ atoms could be embedded inside the carbon phases as $\mathrm{K}$ metallic. The composites have been tested as electro-catalyst in the $\mathrm{CO}_{2}$ reduction to hydrocarbons, and all of them promoted the formation of $\mathrm{C} 1$ to $\mathrm{C} 4$ hydrocarbons with different activity: $\mathrm{PCo}>\mathrm{PNi}>\mathrm{PFe}$, which is in accordance with the apparent faradaic efficiencies. It should be highlighted that PCo shows high selectivity to $\mathrm{C} 3$ products within this group of compounds.

Author Contributions: A.F.P.-C. and F.C.-M. conceived and designed the experiments; J.C.-Q. and A.E. performed the experiments; A.F.P.-C., F.C.-M. and F.J.M.-H. analyzed the data; A.F.P.-C. and F.C.-M. wrote the paper.

Acknowledgments: This research is supported by the FEDER and Spanish projects CTQ2013-44789-R (MINECO) and P12-RNM-2892 (Junta de Andalucía). J.C.-Q. is grateful to the Junta de Andalucía for her research contract (P12-RNM-2892). A.E. acknowledges a predoctoral fellowship from Erasmus Mundus, Al-Idrissi, programme.

Conflicts of Interest: The authors declare no conflict of interest.

\section{References}

1. World Meteorological Organization. Available online: http://www.wmo.int/ (accessed on 1 May 2018).

2. Centi, G.; Perathoner, S. Opportunities and prospects in the chemical recycling of carbon dioxide to fuels. Catal. Today 2009, 148, 191-205. [CrossRef]

3. Stevenson, K. The origin, development, and future of the lithium-ion battery. J. Solid State Electrochem. 2012, 16, 2017-2018. [CrossRef]

4. Bevilacqua, M.; Filippi, J.; Miller, H.A.; Vizza, F. Recent technological progress in $\mathrm{CO}_{2}$ electroreduction to fuels and energy carriers in aqueous environments. Energy Technol. 2015, 3, 197-210. [CrossRef]

5. Hori, Y.; Murata, A. Electrochemical evidence of intermediate formation of adsorbed $\mathrm{CO}$ in cathodic reduction of $\mathrm{CO}_{2}$ at a nickel electrode. Electrochim. Acta 1990, 35, 1777-1780. [CrossRef]

6. Hori, Y.; Murata, A.; Takahashi, R. Formation of hydrocarbons in the electrochemical reduction of carbon dioxide at a copper electrode in aqueous solution. J. Chem. Soc. Faraday Trans. 1989, 85, 2309-2326. [CrossRef]

7. Hori, Y.; Wakebe, H.; Tsukamoto, T.; Koga, O. Electrocatalytic process of CO selectivity in electrochemical reduction of $\mathrm{CO}_{2}$ at metal electrodes in aqueous media. Electrochim. Acta 1994, 39, 1833-1839. [CrossRef]

8. Jitaru, M.; Lowy, D.A.; Toma, M.; Toma, B.C.; Oniciu, L. Electrochemical reduction of carbon dioxide on flat metallic cathodes. J. Appl. Electrochem. 1997, 27, 875-889. [CrossRef]

9. Gattrell, M.; Gupta, N.; Co, A. A review of the aqueous electrochemical reduction of $\mathrm{CO}_{2}$ to hydrocarbons at copper. J. Electroanal. Chem. 2006, 594, 1-19. [CrossRef]

10. Chaplin, R.P.S.; Wragg, A.A. Effects of process conditions and electrode material on reaction pathways for carbon dioxide electroreduction with particular reference to formate formation. J. Appl. Electrochem. 2003, 33, 1107-1123. [CrossRef]

11. Zhang, R.; Lv, W.; Li, G.; Lei, L. Electrochemical reduction of $\mathrm{CO}_{2}$ on $\mathrm{SnO}_{2} /$ nitrogen-doped multiwalled carbon nanotubes composites in $\mathrm{KHCO}_{3}$ aqueous solution. Mater. Lett. 2015, 141, 63-66. [CrossRef]

12. Li, F.; Chen, L.; Knowles, G.P.; MacFarlane, D.R.; Zhang, J. Hierarchical Mesoporous $\mathrm{SnO}_{2}$ Nanosheets on Carbon Cloth: A Robust and Flexible Electrocatalyst for $\mathrm{CO}_{2}$ Reduction with High Efficiency and Selectivity. Angew. Chem. Int. Ed. 2017, 56, 505-509. [CrossRef] [PubMed]

13. Bashir, S.; Hossain, S.; Rahman, S.u.; Ahmed, S.; Amir, A.; Hossain, M.M. Electrocatalytic reduction of carbon dioxide on $\mathrm{SnO}_{2}$ /MWCNT in aqueous electrolyte solution. J. $\mathrm{CO}_{2}$ Util. 2016, 16, 346-353. [CrossRef]

14. Zhu, D.D.; Liu, J.L.; Qiao, S.Z. Recent Advances in Inorganic Heterogeneous Electrocatalysts for Reduction of Carbon Dioxide. Adv. Mater. 2016, 28, 3423-3452. [CrossRef] [PubMed]

15. Centi, G.; Perathoner, S.; Wine, G.; Gangeri, M. Electrocatalytic conversion of $\mathrm{CO}_{2}$ to long carbon-chain hydrocarbons. Green Chem. 2007, 9, 671-678. [CrossRef]

16. Centi, G.; Perathoner, S. Problems and perspectives in nanostructured carbon-based electrodes for clean and sustainable energy. Catal. Today 2010, 150, 151-162. [CrossRef]

17. Li, W.; Seredych, M.; Rodriguez-Castellon, E.; Bandosz, T.J. Metal-free nanoporous carbon as a catalyst for electrochemical reduction of $\mathrm{CO}_{2}$ to $\mathrm{CO}$ and $\mathrm{CH}_{4}$. ChemSusChem 2016, 9, 606-616. [CrossRef] [PubMed] 
18. Perez-Cadenas, A.F. Doped Carbon Material for the Electrocatalytic Conversion of $\mathrm{CO}_{2}$ into Hydrocarbons, Uses of the Material and Conversion Method Using Said Material. Patent WO/2013/004882, 1 October 2013.

19. Perez-Cadenas, A.F.; Ros, C.H.; Morales-Torres, S.; Perez-Cadenas, M.; Kooyman, P.J.; Moreno-Castilla, C.; Kapteijn, F. Metal-doped carbon xerogels for the electro-catalytic conversion of $\mathrm{CO}_{2}$ to hydrocarbons. Carbon 2013, 56, 324-331. [CrossRef]

20. Schouten, K.J.P.; Kwon, Y.; van der Ham, C.J.M.; Qin, Z.; Koper, M.T.M. A new mechanism for the selectivity to $\mathrm{C} 1$ and $\mathrm{C} 2$ species in the electrochemical reduction of carbon dioxide on copper electrodes. Chem. Sci. 2011, 2, 1902-1909. [CrossRef]

21. Qiao, J.; Liu, Y.; Hong, F.; Zhang, J. A review of catalysts for the electroreduction of carbon dioxide to produce low-carbon fuels. Chem. Soc. Rev. 2014, 43, 631-675. [CrossRef] [PubMed]

22. Abdelwahab, A.; Castelo-Quibén, J.; Pérez-Cadenas, M.; Elmouwahidi, A.; Maldonado-Hódar, F.J.; Carrasco-Marín, F.; Pérez-Cadenas, A.F. Cobalt-doped carbon gels as electro-catalysts for the reduction of $\mathrm{CO}_{2}$ to hydrocarbons. Catalysts 2017, 7, 25. [CrossRef]

23. Castelo-Quiben, J.; Abdelwahab, A.; Perez-Cadenas, M.; Morales-Torres, S.; Maldonado-Hodar, F.J.; Carrasco-Marin, F.; Perez-Cadenas, A.F. Carbon-iron electro-catalysts for $\mathrm{CO}_{2}$ reduction. The role of the iron particle size. J. $\mathrm{CO}_{2}$ Util. 2018, 24, 240-249. [CrossRef]

24. Keane, M.A. Catalytic Transformation of Waste Polymers to Fuel Oil. ChemSusChem 2009, 2, $207-214$. [CrossRef] [PubMed]

25. Aguado, J.; Serrano, D.P.; San Miguel, G.; Castro, M.C.; Madrid, S. Feedstock recycling of polyethylene in a two-step thermo-catalytic reaction system. J. Anal. Appl. Pyrol. 2007, 79, 415-423. [CrossRef]

26. Quicker, P. Thermal Treatment as a Chance for Material Recovery. In Source Separation and Recycling: Implementation and Benefits for a Circular Economy; Maletz, R., Dornack, C., Ziyang, L., Eds.; Springer International Publishing: Cham, Switzerland, 2018; pp. 119-149.

27. Bazargan, A.; McKay, G. A review-Synthesis of carbon nanotubes from plastic wastes. Chem. Eng. J. 2012, 195, 377-391. [CrossRef]

28. Huerta-Pujol, O.; Soliva, M.; Giró, F.; López, M. Heavy metal content in rubbish bags used for separate collection of biowaste. Waste Manag. 2010, 30, 1450-1456. [CrossRef] [PubMed]

29. Yang, K.; Yang, Q.; Li, G.; Sun, Y.; Feng, D. Morphology and mechanical properties of polypropylene/calcium carbonate nanocomposites. Mater. Lett. 2006, 60, 805-809. [CrossRef]

30. Maldonado-Hodar, F.J.; Moreno-Castilla, C.; Rivera-Utrilla, J.; Hanzawa, Y.; Yamada, Y. Catalytic graphitization of carbon aerogels by transition metals. Langmuir 2000, 16, 4367-4373. [CrossRef]

31. Maldonado-Hodar, F.J.; Moreno-Castilla, C.; Perez-Cadenas, A.F. Surface morphology, metal dispersion, and pore texture of transition metal-doped monolithic carbon aerogels and steam-activated derivatives. Microporous Mesoporous Mater. 2004, 69, 119-125. [CrossRef]

32. Goncalves, M.R.; Gomes, A.; Condeco, J.; Fernandes, R.; Pardal, T.; Sequeira, C.A.C.; Branco, J.B. Selective electrochemical conversion of $\mathrm{CO}_{2}$ to $\mathrm{C}_{2}$ hydrocarbons. Energy Convers. Manag. 2010, 51, 30-32. [CrossRef] 